\title{
Viscose-based porous carbon fibers: improving yield and porosity through optimization of the carbonization process by design of experiment
}

\author{
Stefan Breitenbach ${ }^{1,2}$. Christoph Unterweger ${ }^{1} \cdot$ Alexander Lumetzberger $^{3} \cdot$ Jiri Duchoslav $^{3,4} \cdot$ David Stifter $^{3}$. \\ Achim Walter Hassel $^{2} \mathbb{D} \cdot$ Christian Fürst $^{1}$
}

Accepted: 26 December 2020 / Published online: 18 January 2021

(c) The Author(s) 2021

\begin{abstract}
In this study, the production of porous carbon fibers from viscose fibers was investigated. The effects of final carbonization temperature $\left(600-1000{ }^{\circ} \mathrm{C}\right)$ and heating rate $\left(6-600{ }^{\circ} \mathrm{C} \mathrm{h}^{-1}\right)$, which determine the carbonization process, on carbon yield, and specific surface area were investigated using a central composite design. The statistical models found were then used to optimize both the yield and the porosity of the carbonized fibers, which are the most important factors for further use as precursors for activated carbon fibers. Despite the contrary effects, porous carbon fibers with a yield of $21.2 \%$ could be produced, which at the same time have a specific surface area of $175 \mathrm{~m}^{2} \mathrm{~g}^{-1}$. The fibers produced were also characterized by SEM, FTIR and Raman spectroscopy, XRD and CHNS analysis.
\end{abstract}

Keywords Porosity $\cdot$ Carbonization $\cdot$ Carbon fibers $\cdot$ Design of experiments $\cdot$ Optimization

\section{Introduction}

Cellulose, the main component of plant cell walls, is the most abundant organic compound on the planet [1]. Due to this unique status as a renewable and environmentally friendly raw material, cellulose plays an important economic and technical role [2]. One of the most important industries depending on cellulose is the textile industry, where cellulose fibers account for a third of all textile fibers. With a production of more than 5 million tons per year, the production of viscose fibers is of essential importance for this economic sector [3]. It is estimated that the production of such viscose fibers will even further increase by $3.1 \%$ per year [4].

Stefan Breitenbach

s.breitenbach@wood-kplus.at

1 Wood K plus - Kompetenzzentrum Holz GmbH, 4040 Linz, Austria

2 Institute of Chemical Technology of Inorganic Materials (TIM), Johannes Kepler University Linz, 4040 Linz, Austria

3 Center for Surface and Nanoanalytics (ZONA), Johannes Kepler University Linz, 4040 Linz, Austria

4 Centre for Electrochemical Surface Technology (CEST), Viktor Kaplan Straße 2, 2700 Wiener Neustadt, Austria
In Germany alone, 1.5 million tons of old clothes are collected every year, and the trend is rising. Only about $43 \%$ of this quantity is suitable for the second-hand market. Apart from its use as insulation material and cleaning utensils, the rest (approx. 20\%, 300,000 tons) has to be disposed of. One way to recycle these waste products from viscose is to convert them into porous carbon fibers. Even if the carbon fibers obtained in this way do not find application in lightweight construction or for the reinforcement of extrusion parts due to their low strength, they are still useful as source material for activated carbon. Activated carbon has a large application potential, from electrode materials for supercapacitors [5-7] and batteries $[8,9]$ to air $[10,11]$ and water filters [12, 13], storage media [14-17] and catalytic support [18, 19].

This work aims to carbonize viscose fibers in such a way that they have a high yield and at the same time the highest possible specific surface area to obtain well-suited precursor materials for activated carbon fibers [3, 20, 21]. Instead of treating the precursor with alkali metal hydroxides and thus carbonizing and activating the fibers in one step, a twostage process was chosen in which the carbonization can be observed separately from the activation. In the second step, the carbonized fibers can be physically activated, with the advantage compared to chemical activation, that the fibers do not have to be washed and no foreign atoms are introduced 
Table 1 Independent variables and their levels for the CCD

\begin{tabular}{llllllll}
\hline Independent variables & Unit & Symbol & \multicolumn{6}{l}{ Coded variable levels } \\
\cline { 3 - 7 } & & & -1.682 & -1 & 0 & +1 & +1.682 \\
\hline Final carbonization temperature & ${ }^{\circ} \mathrm{C}$ & $\mathrm{A}$ & 600 & 659 & 800 & 941 & 1000 \\
Carbonization heating rate & ${ }^{\circ} \mathrm{C} \mathrm{h}^{-1}$ & $\mathrm{~B}$ & 6 & 93 & 303 & 513 & 600 \\
\hline
\end{tabular}

[22-24]. The final carbonization temperature was limited to a maximum of $1000^{\circ} \mathrm{C}$, as higher temperatures are known to reduce the specific surface area of porous carbons [21]. The lower temperature limit of $600{ }^{\circ} \mathrm{C}$ was selected to achieve the complete carbonization of the fibers [25]. To explore the fundamentals of the carbonization process, newly produced viscose fibers are used instead of discarded ones to ensure a consistent quality of the starting fiber and to exclude influences by other materials. In contrast to previous literature, both the carbonization temperature and the heating rate are to be investigated [26, 27]. So far, there has been little research interest in optimizing the surface area [28]. If the influence of the carbonization conditions on the specific surface area was examined, then a one-factor-at-a-time approach was usually chosen instead of also investigating interactions between the individual factors using statistical analysis. A design of experiments approach also has the great advantage that it proposes parameters for optimization after successful modeling of response surfaces [29]. In this way, the optimal carbonization conditions can be found concerning yield and specific surface area for viscose fibers.

\section{Materials and methods}

\subsection{Materials}

Viscose fibers (1.7 dtex, $39 \mathrm{~mm}$, Lenzing AG, Austria) were washed thoroughly with distilled water and dried in an oven at $90{ }^{\circ} \mathrm{C}$ for $24 \mathrm{~h}$. After drying, the residual moisture was determined using a moisture analyzer (MX-50, A\&D Company, Japan) at $105{ }^{\circ} \mathrm{C}$ until the mass remained constant (EN 322). To determine the ash content, $5 \mathrm{~g}\left(\mathrm{w}_{1}\right)$ of dried fibers were incinerated at $525{ }^{\circ} \mathrm{C}$ in a muffle furnace until mass constancy $\left(\mathrm{w}_{2}\right)$ was reached [30]. The percentage of ash was calculated by:

$\mathrm{Ash}=\left(\frac{\mathrm{w}_{2}}{\mathrm{w}_{1}}\right) \cdot 100 \%$.

\subsection{Carbonization}

The carbonization of the raw precursor was carried out by loading $100 \mathrm{~g}$ into a chamber furnace (HTK $8 \mathrm{~W}$, Carbolite
Gero GmbH, Germany). After the evacuation of the chamber, a nitrogen flow of $100 \mathrm{l} \mathrm{h}^{-1}$ was established. The sample was heated from room temperature to the desired temperature with a chosen heating rate and then held isothermal for $30 \mathrm{~min}$.

\subsection{Experimental design}

Design of experiment, a popular statistic tool for modeling and analysis of multi-parameter processes, was used to optimize the carbonization process. A central composite design (CCD) was employed to design the carbonization experiments. In this study, the effect of two independent variables, A (final carbonization temperature) and B (carbonization heating rate) at three levels was investigated (Table 1). A total of 13 experiments consisting of 4 factorial points, 4 axial points and 5 replicates at the central point were employed (Fig. 1). The data were analyzed using Design Expert software version 10 (stat-Ease Inc., USA).

The relationship between the variables and each response $\mathrm{Y}$ could be described as a second-degree polynomial quadratic equation (2):

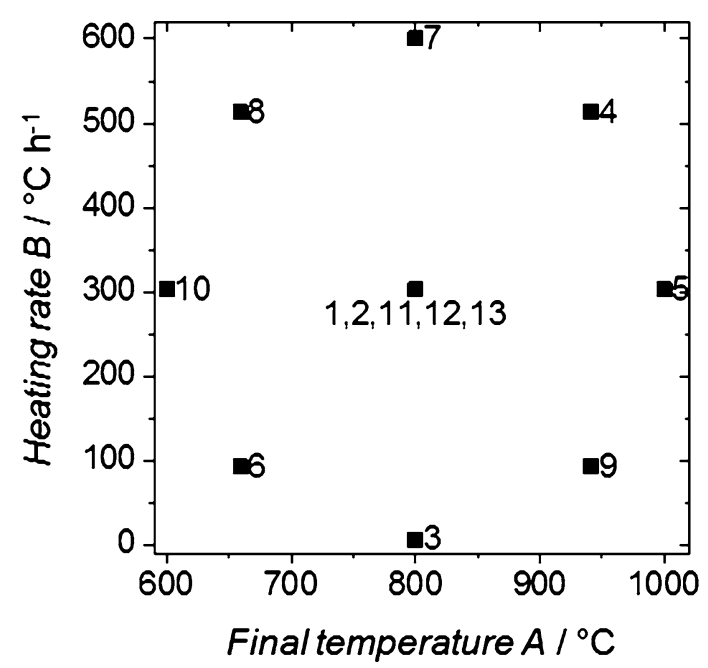

Fig. 1 Visualization of the experimental space used in the CCD. The center point was produced five times to estimate the experimental error. The data points are labeled with the corresponding run numbers 
$\mathrm{Y}=\mathrm{b}_{0}+\sum_{\mathrm{i}=1}^{\mathrm{k}} \mathrm{b}_{\mathrm{i}} \mathrm{x}_{\mathrm{i}}+\sum_{\mathrm{i}=1}^{\mathrm{k}} \mathrm{b}_{\mathrm{ii}} \mathrm{x}_{\mathrm{i}}^{2}+\sum_{\mathrm{i}=1}^{\mathrm{k}-1} \sum_{\mathrm{j}=\mathrm{i}+1}^{\mathrm{k}} \mathrm{b}_{\mathrm{ij}} \mathrm{x}_{\mathrm{i}} \mathrm{x}_{\mathrm{j}}+\varepsilon$,

where $b_{0}$ is the constant value, $b_{i}$ is the regression coefficients of the individual linear effect, $b_{\mathrm{ii}}$ is the quadratic effect and $b_{i j}$ is the interaction between the variables, $k$ is the number of factors studied ( $\mathrm{k}=2$ in this case) and $\varepsilon$ the error or noise observed in the response [31].

\subsection{Characterization of the carbonized fibers}

\subsubsection{Specific surface area}

To determine the specific surface area, carbon dioxide adsorption isotherms at $-78{ }^{\circ} \mathrm{C}$ were determined by an automatic volumetric sorption analyzer (Autosorb-iQ, Anton Paar GmbH, Austria). The adsorbed gas volume on 60-70 mg of the sample was measured at a relative pressure range of 0.1-0.4. Specific surface area was calculated by the Brunauer-Emmet-Teller (BET) method. Before the gas sorption measurements, the samples were outgassed at $400{ }^{\circ} \mathrm{C}$ for $2 \mathrm{~h}$ under vacuum at a heating rate of $120^{\circ} \mathrm{C} \mathrm{h}^{-1}$.

\subsubsection{Scanning electron microscopy (SEM)}

The electron micrographs were recorded using an Auger Microscope JAMP-9500F (JEOL, Japan). The system was operated with an accelerating voltage of $10 \mathrm{kV}$ and an electron beam current of $20 \mathrm{nA}$, which resulted in a lateral resolution of approx. $20 \mathrm{~nm}$.

\subsubsection{Raman-spectroscopy}

The size and structure of carbon domains in the fiber were evaluated using a LabRAM ARAMIS setup (HORIBA Scientific, Germany). A Nd:YAG laser with a wavelength of $532 \mathrm{~nm}$ and a grating with 600 grooves $/ \mathrm{mm}$ was chosen for operation. For each sample at least 15 measurements on different fibers were performed. Proper fitting of the relevant phonon bands, namely the $\mathrm{D}$ and $\mathrm{G}$ band was done using Lorentzian models, as suggested by Sadezky et al. [32]. Three further Raman active disorder peaks $\left(D_{2}, D_{3}\right.$, and $\mathrm{D}_{4}$ ) appear in the region of the main peaks and have been fitted with two Lorentzian and a Gaussian function [33].

The crystallite size along the basal plane $\left(\mathrm{L}_{\mathrm{a}}\right)$ was calculated by Eq. (3), which was proposed by Ferrari and Robertson [34] They found that for small crystallite sizes $(<20 \mathrm{~nm})$, the peak ratio is proportional to $\mathrm{L}_{\mathrm{a}}{ }^{2}$ and not to
$1 / \mathrm{L}_{\mathrm{a}}$. The variables $\mathrm{I}_{\mathrm{G}}$ and $\mathrm{I}_{\mathrm{D}}$ are the peak areas of the corresponding G- and D-bands [35, 36].

$\mathrm{L}_{\mathrm{a}}^{2}=\frac{\mathrm{I}_{\mathrm{D}}}{0.55 \cdot \mathrm{I}_{\mathrm{G}}}$.

\subsubsection{Fourier-transform infrared (FTIR) spectroscopy}

A VERTEX70 (PIKE GladiATR, Bruker, USA) spectrometer was used for IR-measurements using the transmittance mode. A background spectrum was recorded before the experiments. A total of 64 spectra per measurement in the range of $600-4000 \mathrm{~cm}^{-1}$ with a resolution of $2 \mathrm{~cm}^{-1}$ were recorded. Subsequently, the spectrum was baseline corrected and evaluated using the OPUS software.

\subsubsection{CHNS-analysis}

The elementary composition of the precursor and the samples produced was determined using a FlashEA 1112 (Thermo Fisher Scientific, Inc., USA). The temperature of the furnace was $900{ }^{\circ} \mathrm{C}$, the oxygen flow was $250 \mathrm{ml} \mathrm{min}^{-1}$. A $2 \mathrm{~m}$ long Porapak GC column was used to separate the gases.

\subsubsection{X-ray diffraction (XRD)}

Crystallinity studies were performed using XRD. Before the measurement, the carbonized fibers were ground using a mortar mill (MS10, Retsch, Germany). The XRD patterns were recorded in $2 \theta$ range from $5^{\circ}$ to $50^{\circ}$ using a Philips $\mathrm{X}^{\prime}$ Pert Pro XRD system in Bragg-Brentano geometry operating with $\mathrm{Cu} \mathrm{K} \alpha$-radiation with an acceleration voltage of $45 \mathrm{kV}$.

The recorded spectra were smoothed and baseline corrected. The region below the baseline is attributed to an instrumental background signal which may include air and incoherent scattering. The apparent crystallite size, for a given reflection, was calculated using the Scherrer equation (4) as follows [37]:

$\mathrm{L}(\mathrm{hkl})=\frac{\mathrm{K} \cdot \lambda}{\beta \cdot \cos (\theta)}$,

where $\theta$ is the Bragg angle for the reflection concerned, $\lambda$ is the wavelength of the radiation (wavelength of $0.154056 \mathrm{~nm}), \mathrm{L}(\mathrm{hkl})$ is the mean length of the crystallite perpendicular to the planes (hkl), $\beta$ is the width at half maximum intensity, and $\mathrm{K}$ is a Scherrer parameter ( 0.89 for half-widths). 
Table 2 Results of the CHNSmoisture- and ash-analysis of the precursor

\begin{tabular}{|c|c|c|c|c|c|c|}
\hline \multicolumn{4}{|c|}{ Chemical composition/wt $\%$} & \multicolumn{2}{|c|}{ Proximate analysis/wt $\%$} & \multirow{2}{*}{$\begin{array}{l}\text { Rest (most } \\
\text { likely O)/ } \\
\text { wt\% }\end{array}$} \\
\hline $\mathrm{C}$ & $\mathrm{H}$ & $\mathrm{N}$ & S & Moisture & Ash & \\
\hline 40.21 & 6.20 & 0.00 & 0.00 & 4.16 & 0.32 & 49.11 \\
\hline
\end{tabular}

Table 3 Experimental design matrix and results of the carbonization

\begin{tabular}{lrrll}
\hline Run & $\mathrm{A} /{ }^{\circ} \mathrm{C}$ & $\mathrm{B} /{ }^{\circ} \mathrm{C} \mathrm{h}^{-1}$ & $\mathrm{Y}_{1} / \%$ & $\mathrm{Y}_{2} / \mathrm{m}^{2} \mathrm{~g}^{-1}$ \\
\hline 1 & 800 & 303 & 18.22 & 155.0 \\
2 & 800 & 303 & 18.27 & 152.9 \\
3 & 800 & 6 & 21.15 & 174.9 \\
4 & 941 & 513 & 17.61 & 130.1 \\
5 & 1000 & 303 & 17.87 & 102.3 \\
6 & 659 & 93 & 20.10 & 157.3 \\
7 & 800 & 600 & 16.84 & 160.1 \\
8 & 659 & 513 & 17.67 & 145.2 \\
9 & 941 & 93 & 19.29 & 144.6 \\
10 & 600 & 303 & 18.83 & 127.5 \\
11 & 800 & 303 & 18.24 & 157.5 \\
12 & 800 & 303 & 18.26 & 154.2 \\
13 & 800 & 303 & 18.14 & 157.2 \\
\hline
\end{tabular}

\section{Results and discussion}

The chemical composition of the viscose fibers and the results of moisture and ash analysis have been determined at least twice and are shown in Table 2. At $0.32 \%$, the ash content determined in this way is relatively low compared to the literature [38]. The deviations from pure cellulose result from residual moisture. The difference between the summed values and $100 \mathrm{wt} \%$ represents mainly the proportion of oxygen that is not bound as water and could not be analyzed directly. This results in an O content of $49.11 \mathrm{wt} \%$.

Table 3 shows the experimental conditions for the preparation of the carbonized fibers generated by Design Expert software. The fibers are characterized by yield $\left(\mathrm{Y}_{1}\right)$, and specific surface area $\left(\mathrm{Y}_{2}\right)$; the results are listed in Table 3 as well.

\subsection{Analysis of variance (ANOVA)}

To analyze how adequate the chosen models are, analysis of variance (ANOVA) was applied at a confidence level of $95 \%$. The ANOVA data for the coded quadratic models for the responses are shown in Tables 4 and 5. Based on the ANOVA analysis for the carbonization yield, the significant effects are final carbonization temperature (A), heating rate $(B)$ and the interaction effects $A B, A^{2}$, and $\mathrm{B}^{2}$. The final model in terms of coded factors for the yield $\left(\mathrm{Y}_{1}\right)$ is shown in Eq. (5).

$Y_{1}=18.0-0.28 \mathrm{~A}-1.28 \mathrm{~B}+0.19 \mathrm{AB}+0.06 \mathrm{~A}^{2}+0.38 \mathrm{~B}^{2}$,

Both the carbonization temperature and the heating rate have a negative effect on the yield. Therefore, an increased carbonization temperature or heating rate results in a lower yield. However, the interaction of two factors seems to have an inverse effect. The response model for the specific surface area $\left(\mathrm{Y}_{2}\right)$ is shown in Eq. (6).

$\mathrm{Y}_{2}=155.36-7.94 \mathrm{~A}-5.94 \mathrm{~B}-0.60 \mathrm{AB}-19.49 \mathrm{~A}^{2}+6.82 \mathrm{~B}^{2}$.

Fischer variance values (F-value), defined as the model mean square divided by the error mean square, were compared with critical F-value, which is $\mathrm{F}_{0.05,5,7}=3.97$ for both models $(0.05$ is the false-rejection probability, 5 is the degree of freedom of regression, and 7 is the degree of freedom of residual error) [29].
Table 4 ANOVA of the yield $\left(\mathrm{Y}_{1}\right)$

\begin{tabular}{lcccrrr}
\hline Source & Sum of squares & Df & Mean square & F-value & p-value Prob $>$ F & \\
\hline Model & 14.80 & 5 & 2.96 & 38.95 & $<0.0001$ & Significant \\
A & 0.62 & 1 & 0.62 & 8.16 & 0.0244 & \\
B & 13.02 & 1 & 13.02 & 171.31 & $<0.0001$ & \\
AB & 0.14 & 1 & 0.14 & 1.84 & 0.2167 & \\
$\mathrm{~A}^{2}$ & 0.025 & 1 & 0.025 & 0.32 & 0.5866 \\
B $^{2}$ & 1.02 & 1 & 1.02 & 13.37 & 0.0081 \\
Residual & 0.53 & 7 & 0.076 & & & \\
Cor total & 15.33 & 12 & & & &
\end{tabular}


Table 5 ANOVA of the specific surface area $\left(\mathrm{Y}_{2}\right)$

\begin{tabular}{lcccrcr}
\hline Source & Sum of squares & Df & Mean square & F-value & p-value Prob $>$ F & \\
\hline Model & 4044.50 & 5 & 808.90 & 126.32 & $<0.0001$ & Significant \\
A & 503.23 & 1 & 503.23 & 78.59 & $<0.0001$ & \\
B & 282.39 & 1 & 282.39 & 44.10 & 0.0003 & \\
AB & 1.44 & 1 & 1.44 & 0.22 & 0.6498 & \\
$\mathrm{~A}^{2}$ & 2634.37 & 1 & 2634.37 & 411.39 & $<0.0001$ & \\
$\mathrm{~B}^{2}$ & 322.99 & 1 & 322.99 & 50.44 & 0.0002 & \\
Residual & 44.82 & 7 & 6.40 & & & \\
Cor total & 4089.32 & 12 & & & &
\end{tabular}

At 38.95, the F-value for the yield of the carbonized fibers is about 10 times higher than the critical F-value, which makes the model significant. There is only a $0.01 \%$ chance that a "Model F-value" this large could occur due to noise. The significance of each coefficient is evaluated by an individual p-value. The lower the p-value, the more significant is the variable. With a p-value of less than 0.05 , the terms $\mathrm{A}, \mathrm{B}$ and $\mathrm{B}^{2}$ are significant model terms. Thus, both the carbonization temperature and the heating rate have a significant influence on the yield. The F-value of the quadratic models for the specific surface area is with 126.32 very high, indicating a high significance [40]. The probability that such an F-value will result from background noise is only $0.01 \%$. Here, the final carbonization temperature is the most significant parameter with a $\mathrm{p}$-value lower than 0.0001 . In addition, the heating rate is also significant with a p-value of 0.0003 as well as both quadratic terms $\mathrm{A}^{2}$ and $\mathrm{B}^{2}$.

\subsection{Response surface analysis}

\subsubsection{Yield}

The relationship between yield, carbonization temperature, and heating rate as provided by the selected model is graphically illustrated in Fig. 2. Overall, the model fits well with the sample points; practically all points are located on the response surface. The center points, which were produced 5 times, show only a small standard deviation of $0.046 \%$.

The yield can be significantly increased over the entire temperature range by reducing the heating rate. The influence of temperature is low, especially at high heating rates, but at slow heating rates, the yield decreases with increasing temperature. This decrease in yield with increasing temperature has already been observed for other cellulose-based precursors [21, 26, 41, 42]. The lowest yield of $16.9 \%$ according to the model prediction is achieved with high temperature $\left(1000^{\circ} \mathrm{C}\right)$ and a fast heating rate $\left(600^{\circ} \mathrm{C} \mathrm{h}^{-1}\right)$. A theoretical maximum yield of $21.7 \%$ can be achieved with a slow heating rate and low temperature.

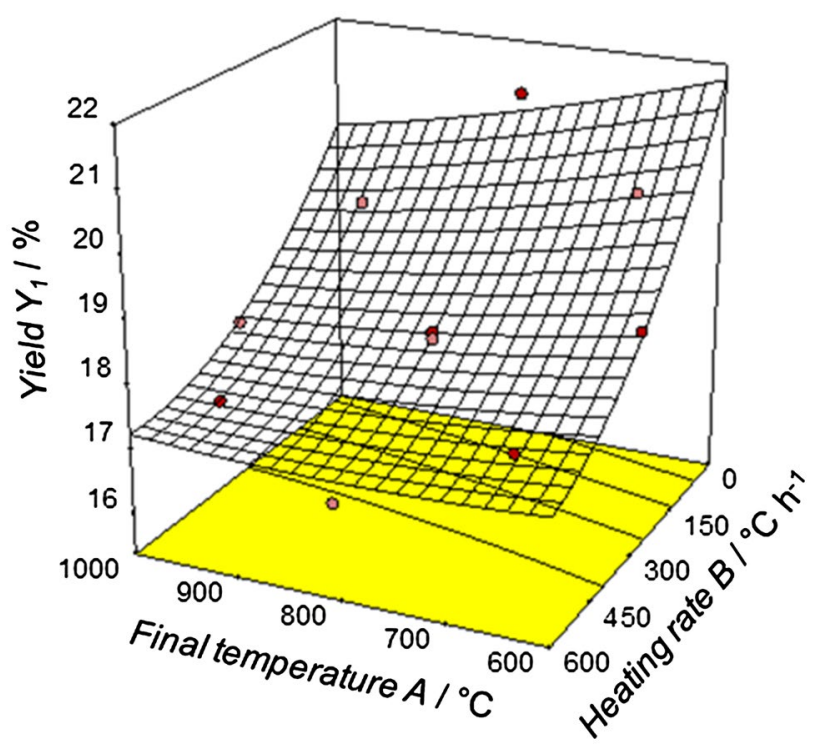

Fig. 2 Surface response plot for the carbonization yield

The high increase in yield at slow heating rates shows good agreement with previous work [43]. Even after the deduction of the residual moisture and ash content, the actual yield achieved remains below the $29.5 \%$ postulated by Tang's four-carbon residue model $[44,45]$. To achieve such high yields, an even slower heating rate than tested here is necessary.

\subsubsection{Specific surface area}

To determine the specific surface area of the carbonized fibers, adsorption isotherms with carbon dioxide at $-78{ }^{\circ} \mathrm{C}$ were recorded. The reactions taking place during carbonization are relatively complex [3]. In general, cellulose is depolymerized with increasing temperature, rearranged and condensed to polycyclic rings and aromatic structures and finally to graphene-like layers $[3,25,44]$. The result is a microcrystalline material consisting of $\mathrm{sp}^{2}$ and $\mathrm{sp}^{3}$ hybridized carbon. The specific surface area results from the gaps between these graphitic microcrystals [46]. 


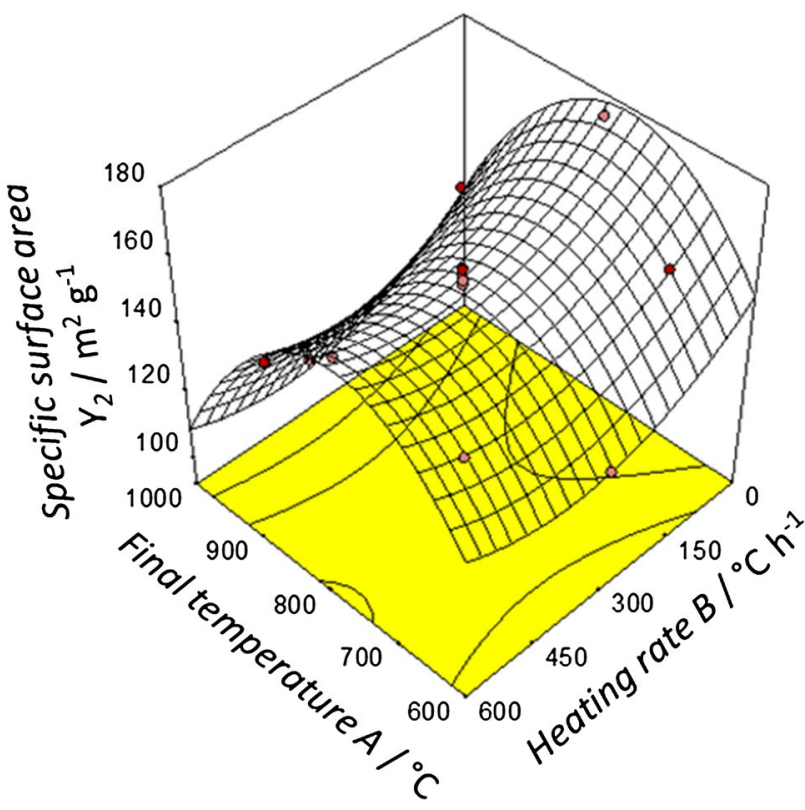

Fig. 3 Surface response plot for the specific surface area after carbonization

The surface response plot of the specific surface area determined by $\mathrm{CO}_{2}$-physisorption is shown in Fig. 3. It was found that the measurement points were in good agreement with the model, with the centers scattering only by \pm 1.76 $\mathrm{m}^{2} \mathrm{~g}^{-1}$. Overall, no clear trend of individual factors could be observed which is also because the AB term in the model is significant. The specific surface area increases with a slower heating rate at high temperatures but decreases at lower temperatures in the observed experimental space. Also, the surface grows with a slow carbonization heating rate as the temperature rises, but no clear trend can be observed for fast heating rates.

The increase in specific surface area with rising temperature can be attributed to an increase in volatile components released from the carbon structure. In addition, as the temperature rises, pores blocked by released tars are liberated [47]. The reduction of the surface area with further increasing temperature is attributed by Lua et al. to a decomposition reaction, whereby volatile components block pores again, thereby reducing the surface area [48]. The increase of the surface area with slower heating rates agrees well with the results of Brunner, who investigated powdered cellulose [43]. According to his results, a further increase should be possible at even slower heating rates (down to $1.8^{\circ} \mathrm{C} \mathrm{h}^{-1}$ ).

The highest specific surface area in the selected model within the test space could be found with $174.9 \mathrm{~m}^{2} \mathrm{~g}^{-1}$ at the medium temperature $\left(800{ }^{\circ} \mathrm{C}\right)$ and a slow heating rate $\left(6^{\circ} \mathrm{C}\right.$ $\left.\mathrm{h}^{-1}\right)$. The lowest surface area $\left(102.3 \mathrm{~m}^{2} \mathrm{~g}^{-1}\right)$ was found at the highest temperature of $1000{ }^{\circ} \mathrm{C}$ and a heating rate of $303^{\circ} \mathrm{C}$ $\mathrm{h}^{-1}$ within the examined test space.

\subsection{Normal probability plots}

The normal probability plots of the residuals (Fig. 4) are used to determine the normality of the data. For this, quantiles of sample data are plotted against quantiles of the standardized theoretical distribution [49]. The closer the data points are to the straight line, the greater the normal distribution of the measurement points [50]. In the case of both responses examined (yield, and specific surface area), the data points suggest a normally distributed population.
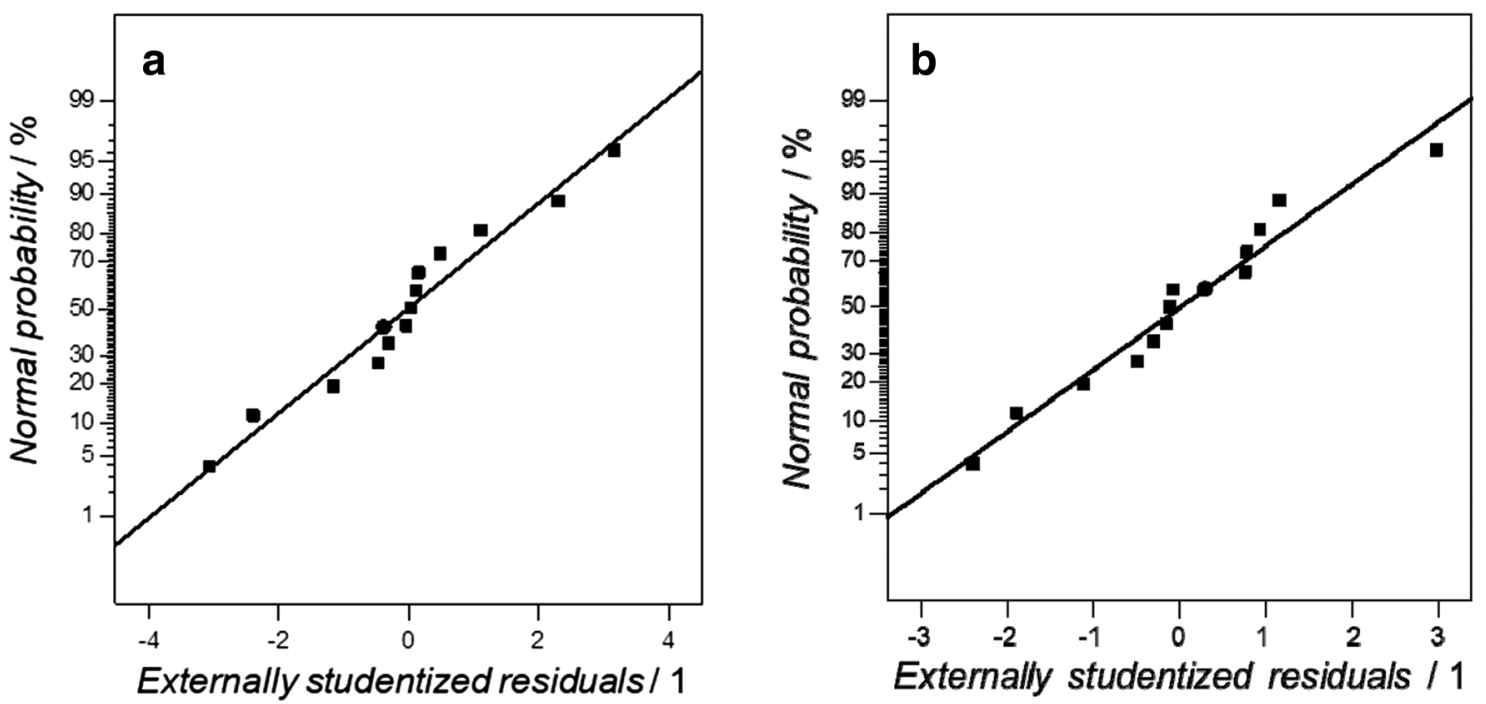

Fig. 4 Normal probability plots of residuals for the three responses: a carbonization yield, and $\mathbf{b}$ specific surface area 
Fig. 5 Actual and by the models predicted values of the yield (a), and the specific surface area (b). The line would mean a perfect congruence of the model and reality

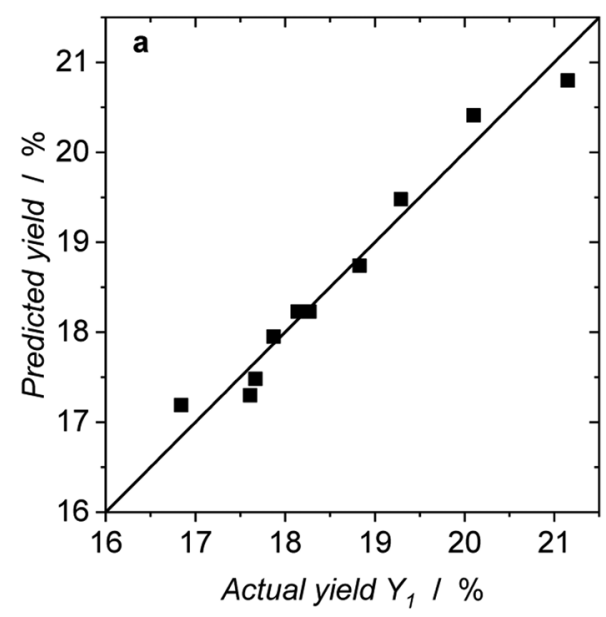

\subsection{Predicted vs. actual data}

The goodness of fit model was used to determine how well the statistical model matches the experimental data. A coefficient $\mathrm{R}^{2}$ as close as possible to 1 stands for high goodness of fit [39]. The actual vs. predicted plots of the responses are shown in Fig. 5. There was a strong correlation between the predicted and actual yield of carbonized fibers $\left(\mathrm{R}^{2}=0.97\right)$ as well as between the predicted and actual specific surface areas $\left(\mathrm{R}^{2}=0.99\right)$. The points are evenly distributed on both sides of the line, which indicates that the respective model is well suited for predicting the correlation between factors and response [51].

\subsection{Optimization process}

Since the yield of carbonization partially shows a contrary trend with temperature and heating rate as the specific surface area, an optimization was performed using design of experiments. The optimizations were carried out within the parameter space $\left(600-1000{ }^{\circ} \mathrm{C}, 6-600{ }^{\circ} \mathrm{C} \mathrm{h}^{-1}\right)$, where the carbonization temperature should be minimized and the heating rate maximized. Both responses needed to be maximized. Since the result of the responses is more important to us than that of the test conditions, the weighting of the conditions was set to 1 , while the weighting of the responses was set to 2 . The optimizations carried out were within the prediction interval (PI) of $95 \%$ (Table 6). At this point it must be noted that the optimized yields and specific surface areas of the fibers do not reach the maximum values already found in the experimental space. This is due to the fact that the manufacturing parameters were also optimized here. Thus, the yields and surface areas achieved here are high, while at the same time the carbonization temperature and heating rate are as low as possible.

\subsection{Structural and textural properties of the carbonized fibers}

\subsubsection{Morphology}

The SEM images of the precursor and the carbonized fiber (Run 1, see Table 3) are shown in Fig. 6. The structure of the fiber, which is caused by the spinning process of the viscose, remains after the carbonization step. However, the fiber diameter shrinks from approx. 9 to approx. $5 \mu \mathrm{m}$ during the carbonization process. A difference in morphology between the different carbonized fibers could not be determined.

\subsubsection{CHNS-analysis}

Elemental analysis was used to investigate the influence of temperature and heating rate during carbonization upon the $\mathrm{C}, \mathrm{H}$ and, indirectly, $\mathrm{O}$ content of the carbonized fibers. The results can be seen in Figs. 7 and 8.

Table 6 Optimizations based on the statistical models

\begin{tabular}{|c|c|c|c|c|c|}
\hline & Response & Prediction & $95 \%$ PI low & 95\% PI high & Validation \\
\hline \multirow[t]{2}{*}{ Optimization 1: $\mathrm{A}=700^{\circ} \mathrm{C} ; \mathrm{B}=162{ }^{\circ} \mathrm{C} \mathrm{h}^{-1}$} & $\mathrm{Y}_{1} / \%$ & 19.57 & 19.24 & 19.90 & 19.32 \\
\hline & $\mathrm{Y}_{2} / \mathrm{m}^{2} \mathrm{~g}^{-1}$ & 158.0 & 155.0 & 161.1 & 156.5 \\
\hline \multirow[t]{2}{*}{ Optimization 2: $\mathrm{A}=675^{\circ} \mathrm{C} ; \mathrm{B}=600{ }^{\circ} \mathrm{C} \mathrm{h}^{-1}$} & $\mathrm{Y}_{1} / \%$ & 17.25 & 16.56 & 17.93 & 17.03 \\
\hline & $\mathrm{Y}_{2} / \mathrm{m}^{2} \mathrm{~g}^{-1}$ & 153.1 & 146.8 & 159.4 & 151.2 \\
\hline
\end{tabular}


Fig. 6 SEM micrographs of the viscose fiber and the carbonized fiber (Run $1 ; \mathrm{A}=800{ }^{\circ} \mathrm{C}$, $\mathrm{B}=303^{\circ} \mathrm{C} \mathrm{h}^{-1}$ )
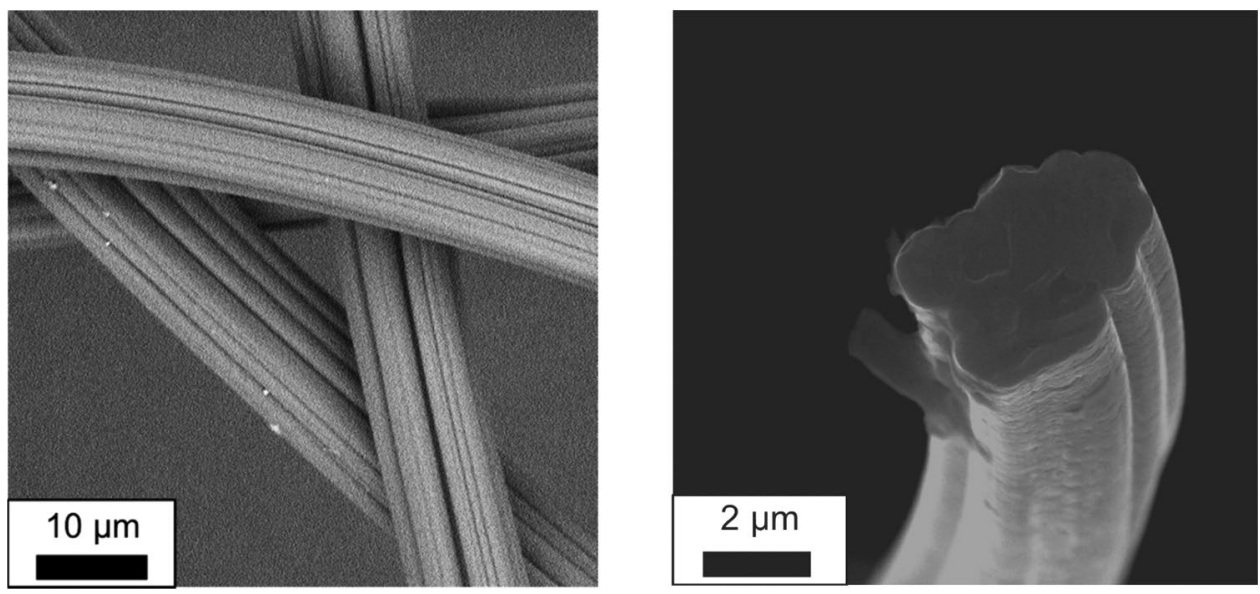

The carbon content increases with increasing temperature (at a heating rate of $303{ }^{\circ} \mathrm{C} \mathrm{h}^{-1}$ ) from 88.2 to $91.8 \%$, while the hydrogen content decreased simultaneously from 2.1 to $0.5 \%$. During carbonization up to $400{ }^{\circ} \mathrm{C}$, most of the non-carbon elements were removed as volatile substances such as $\mathrm{H}_{2} \mathrm{O}, \mathrm{CO}, \mathrm{CO}_{2}$, and tars [44]. Above $400{ }^{\circ} \mathrm{C}$ the aromatization of the carbon structure occurs, forming graphite layers, which results in the release of $\mathrm{H}_{2}[3,52]$. This release of $\mathrm{H}_{2}$ causes the relative carbon content to increase and the hydrogen content to decrease as the temperature rises.

As the carbonization heating rate increases at $800{ }^{\circ} \mathrm{C}$ (Fig. 7b), the relative carbon content is reduced from 92.3 to $88.8 \%$ while the relative hydrogen content is rising from 0.6 to $0.9 \%$. Again, the aromatization of the carbon structure can be used as an argument: The slower heating rate enables the system to convert more completely into graphitic layers, whereby the hydrogen content decreases with increasing heating rate and the carbon content increases. Brunner and Roberts also found that a slower heating rate during carbonization leads to a char with a lower oxygen content due to more complete dehydration [43]. The gentle heating rate of only $6^{\circ} \mathrm{C} \mathrm{h}^{-1}$ also results in nitrogen content of $0.4 \%$, while no nitrogen was detectable under any other conditions.

Since the ash content of the precursor is only $0.32 \%$, it can be assumed that the rest of the sample is oxygen (see Fig. 8). The $\mathrm{O}$ content shows a similar trend as the hydrogen content. The reason for this is the better-formed graphite layers with higher temperatures and lower heating rates.

\subsubsection{FTIR-spectroscopy}

FTIR spectroscopy was used to determine various functionalities of the porous carbon fibers. The spectra of the fibers carbonized at $303{ }^{\circ} \mathrm{C} \mathrm{h}^{-1}$ and different temperatures $\left(600{ }^{\circ} \mathrm{C}, 800{ }^{\circ} \mathrm{C}\right.$, and $\left.1000{ }^{\circ} \mathrm{C}\right)$ can be seen in Fig. 9. Due to the many intermediates that may arise during the carbonization of cellulose, the assignment of the bands is often ambiguous [53]. The bands at 2922 and $2850 \mathrm{~cm}^{-1}$ can be assigned to the $\mathrm{C}-\mathrm{H}$ stretching vibration [54]. The signals decrease significantly with increasing carbonization temperature. The same trend can be observed with the band at $1664 \mathrm{~cm}^{-1}$, which can be assigned to the carbonyl vibration [27]. The signal at $1560 \mathrm{~cm}^{-1}$ can be assigned to highly
Fig. 7 Dependence of the carbon (black; $\mathrm{B}=303{ }^{\circ} \mathrm{C} \mathrm{h}^{-1}$ ) and hydrogen (grey; $\mathrm{A}=800{ }^{\circ} \mathrm{C}$ ) content on carbonization temperature (a) and heating rate (b)
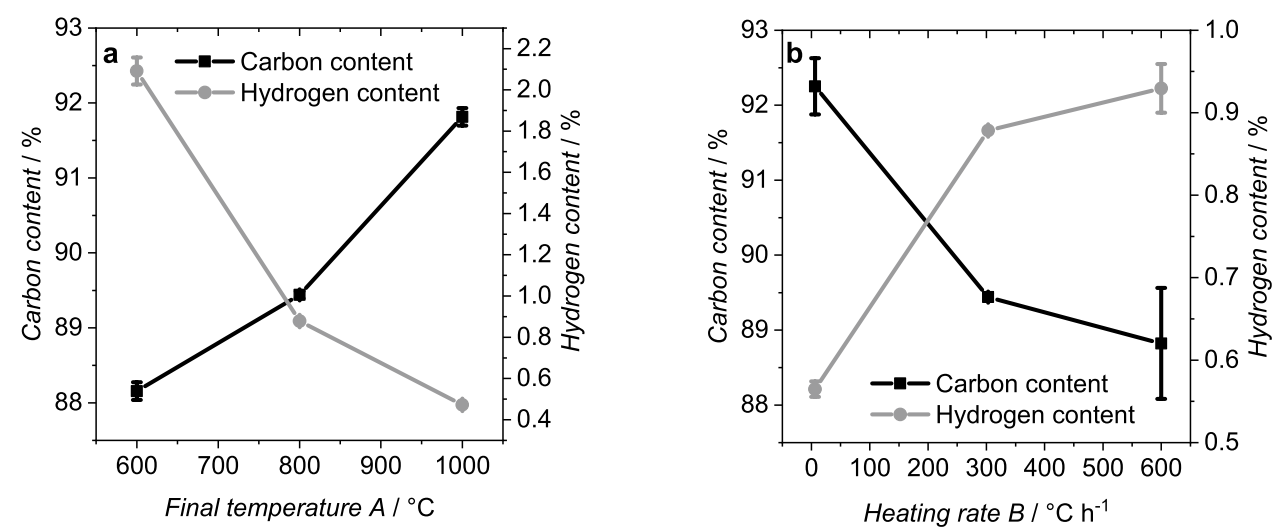
Fig. 8 Dependence of the oxygen content on carbonization temperature (a, $\left.\mathrm{B}=303{ }^{\circ} \mathrm{C} \mathrm{h}^{-1}\right)$ and heating rate $\left(\mathbf{b}, \mathrm{A}=800^{\circ} \mathrm{C}\right)$

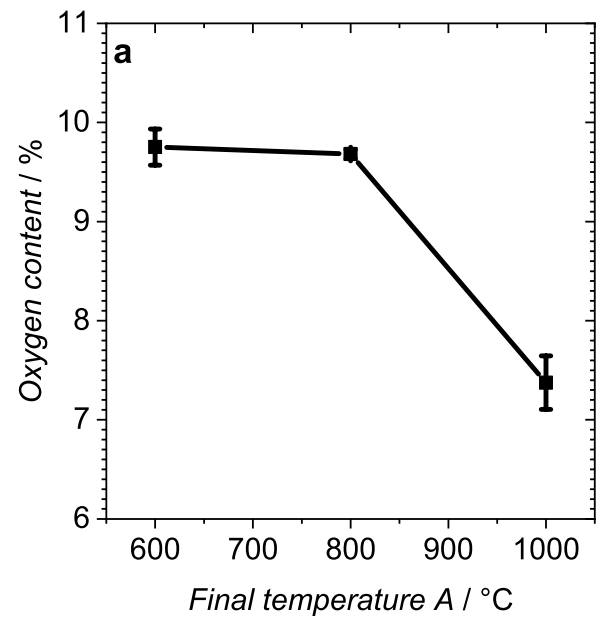

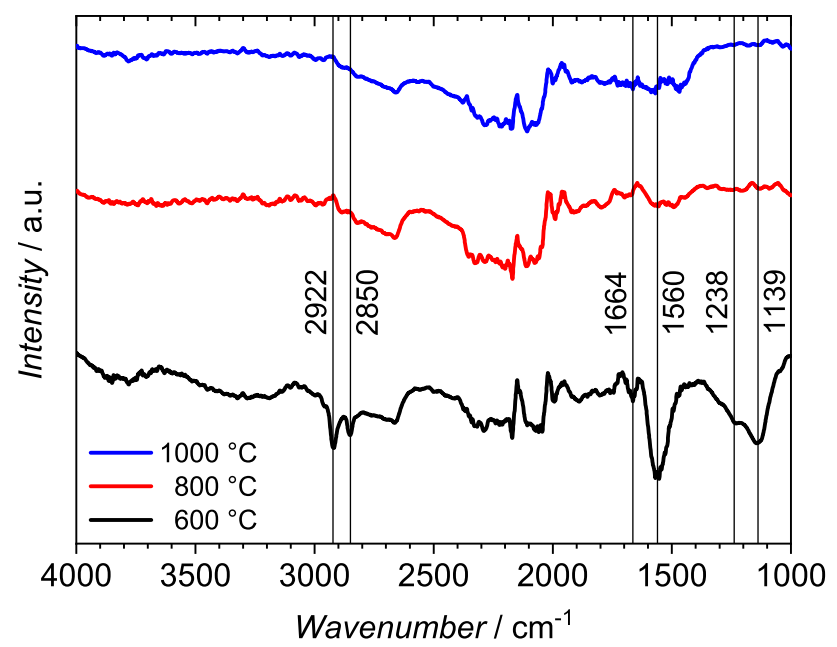

Fig. 9 FTIR-spectra of viscose fibers carbonized at different temperatures (blue: $1000{ }^{\circ} \mathrm{C}$; red: $800{ }^{\circ} \mathrm{C}$; black: $600{ }^{\circ} \mathrm{C}$ ) with a heating rate of $303{ }^{\circ} \mathrm{C} \mathrm{h}^{-1}$. Distinctive bands are marked by vertical lines with corresponding wavenumbers (Color figure oline)

conjugated carbonyl groups $(\mathrm{C}=\mathrm{O})$ [53]. Especially in the range of $1300-1000 \mathrm{~cm}^{-1}$, signals from superpositions of overlapping signals occur, which further complicates the assignment. The band at $1238 \mathrm{~cm}^{-1}$ is often attributed to the $\mathrm{O}-\mathrm{H}$ deformation vibration, but a $\mathrm{C}-\mathrm{O}$ stretch vibration of carbonyl groups is also possible $[10,54]$. The band at $1139 \mathrm{~cm}^{-1}$ can be assigned to an asymmetric $\mathrm{C}-\mathrm{O}-\mathrm{C}$ stretch vibration [54]. Overall, the signals representing $\mathrm{C} / \mathrm{O}$ or $\mathrm{C} / \mathrm{H}$ groups decrease significantly with increasing temperature, which is consistent with the results of the CHNS analysis.

\subsubsection{X-ray diffraction}

The XRD spectra of the carbonized and ground fibers show no sharp peaks, but broad ones, which indicate the presence of amorphous carbon interlayers (Fig. 10) [27, 52, 55].

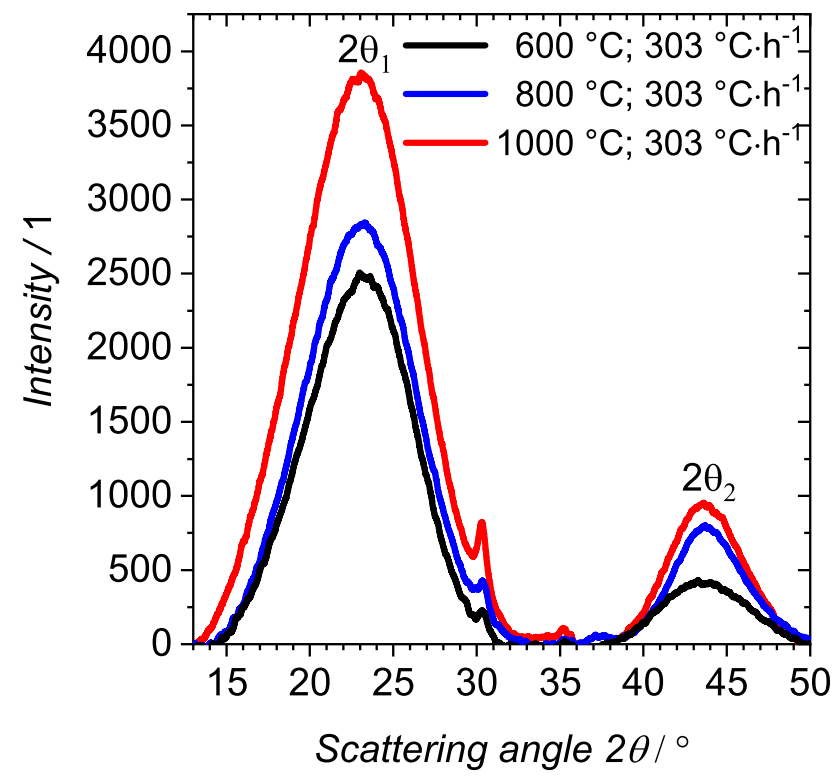

Fig. 10 XRD spectra of the fibers carbonized at different temperatures

These carbon interlayers resemble graphitic crystals, with the difference that they are not stacked in a specific order, therefore they are called turbostratic carbon crystallites [56]. The signal with the maximum at $2 \theta_{1}=23.0^{\circ}-23.3^{\circ}$ can be assigned to the (002) crystallographic plane of graphite crystallite, the reflection with the maximum at $2 \theta_{2}=43.7^{\circ}-43.9^{\circ}$ to the (101) plane [57].

The values of the peak position and the full width at half maximum $(\beta)$ were employed to calculate the interplanar d-spacing and the apparent crystallite size using Eq. (4) as shown in Table 7 . The $\mathrm{d}_{002}$-spacing of the carbonized viscose fibers with values of $0.382-0.385 \mathrm{~nm}$ showed hardly any dependence on the temperature. Overall, the distance between the individual graphite-like layers is thus slightly larger than that in graphite, which is $0.335 \mathrm{~nm}$ [58]. 
Table 7 Peak parameters and calculated values for the carbonized viscose fibers

\begin{tabular}{lllllllll}
\hline Run & $\mathrm{A} /{ }^{\circ} \mathrm{C}$ & $\mathrm{B} /{ }^{\circ} \mathrm{Ch}^{-1}$ & $2 \theta_{1} /{ }^{\circ}$ & $2 \theta_{2} /{ }^{\circ}$ & $\beta_{1} /^{\circ}$ & $\beta_{2}{ }^{\circ}$ & $\mathrm{d}_{002} / \mathrm{nm}$ & $\mathrm{L}_{002} / \mathrm{nm}$ \\
\hline 10 & 600 & 303 & 23.29 & 43.85 & 7.57 & 6.16 & 0.382 & 1.059 \\
1 & 800 & 303 & 23.09 & 43.77 & 7.79 & 5.03 & 0.385 & 1.029 \\
5 & 1000 & 303 & 23.24 & 43.75 & 7.86 & 4.87 & 0.382 & 1.012 \\
\hline
\end{tabular}

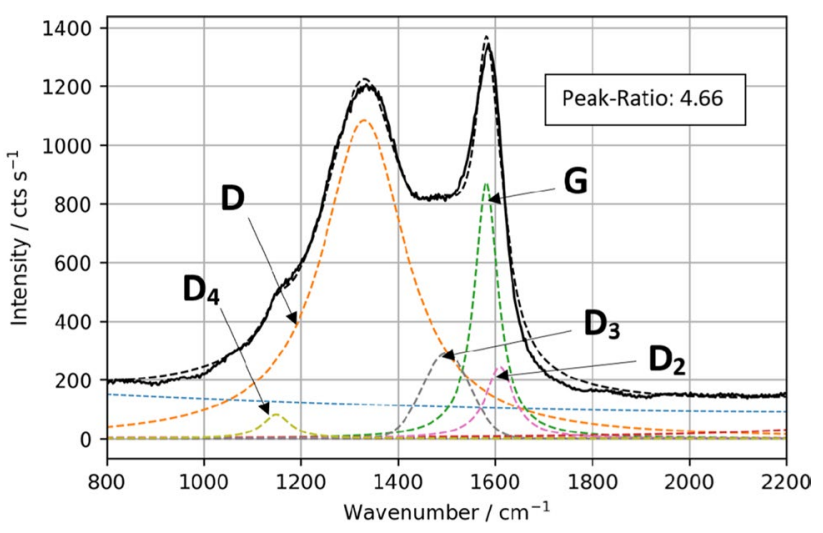

Fig. 11 Raman spectrum of Run 1 and fitted peaks

The crystallite sizes $\mathrm{L}_{002}$ become smaller with increasing temperature (1.059 to $1.012 \mathrm{~nm}$ ). Although this is in contrast to previous results, it could be due to the general shrinkage of the fibers $[52,56]$. Altogether, the structural changes in the observed range are very small since the graphitization takes place especially above $1500^{\circ} \mathrm{C}$.

\subsubsection{Raman spectroscopy}

The structure of the carbonized viscose fibers was further characterized by Raman spectroscopy. This laser-optical technique can determine the bonding states of the carbon atoms $\left(\mathrm{sp}^{2}\right.$ for graphite or $\mathrm{sp}^{3}$ for diamond) by displaying their vibrational properties. As illustrated by the spectrum of a carbonized fiber from Run 1 in an exemplary manner (Fig. 11), a broad D-band is observed. The two main peaks $\mathrm{D}$ and $\mathrm{G}$ are both caused by in-plane phonon modes in a 2D graphite layer. The graphite peak at around $1588 \mathrm{~cm}^{-1}$ arises from $\mathrm{sp}^{2}$ bonded carbons. These can stem from the 6 -fold rings of the graphite domains and chains of carbon in more disordered structures $[34,59,60]$. The disorder peak at around $1327 \mathrm{~cm}^{-1}$ stands for the breathing mode of a 6 -fold carbon ring. This mode only appears within graphite layers and only in the proximity of a defect or border. At these borders, the graphite mode cannot propagate anymore, because of missing $\mathrm{sp}^{2}$ bonding in the hexagonal carbon lattice structure, which is replaced by $\mathrm{sp}^{3}$ bonds [60]. The carbon structure is turbostratic. Therefore, most carbon rings in the lattice contribute to the broad and intense D-band. With the above argumentation, it is often tried to assume the relative amount of $\mathrm{sp}^{3}$ bonds in the fiber. To get a valid fit considered all the existing Raman active phonon modes in the region (see Sect. 2.4.3). Besides the one graphite peak, four disorder bands $\left(D, D_{2}, D_{3}, D_{4}\right)$ were found. Their meaning is not always exactly understood, but they are caused by imperfect graphite structures. Recent publications used this approach for data analyzation successfully [33, 61, 62]. With the consideration of these bands, the resulting fit becomes much more accurate.

One important parameter to characterize the structure of the fiber is the peak ratio. It consists of the areas of the intensities of D and G bands. With it, the crystallite sizes can be calculated and the development of graphite domains inside the fiber is determined. A further value often considered is the full width at half maximum (FWHM). The FWHM always decreases with increasing order of the carbon structure [59].

Table 8 gives the averaged values of all the measurements done with Raman spectroscopy. The FWHM of the disordered peak decreases with increasing temperature, which indicates an increase in the order of the carbon structure [52]. The FWHM of the graphite peak does not show this trend, but as the graphite peak can also occur in carbon chains, not only in graphitic domains, it does not react as much to structural changes [60]. The decrease in FWHM of the D band results from the destruction of crosslinks between aliphatic and aromatic carbons, the volatilization of oxygen-containing functional groups and
Table 8 Analysis of Raman spectra obtained from the carbonization of viscose fibers at different final temperatures (A) and heating rates (B)

\begin{tabular}{lllllll}
\hline Run & $\mathrm{A} /{ }^{\circ} \mathrm{C}$ & $\mathrm{B} /{ }^{\circ} \mathrm{Ch}^{-1}$ & $\mathrm{FWHM}_{\mathrm{D}} / \mathrm{cm}^{-1}$ & $\mathrm{FWHM}_{\mathrm{G}} / \mathrm{cm}^{-1}$ & $\mathrm{I}_{\mathrm{D}} / \mathrm{I}_{\mathrm{G}}$ & $\mathrm{L}_{\mathrm{a}} / \mathrm{nm}$ \\
\hline 10 & 600 & 303 & 224.61 & 56.78 & 3.56 & 2.54 \\
1 & 800 & 303 & 203.59 & 54.28 & 4.66 & 2.91 \\
5 & 1000 & 303 & 190.10 & 57.38 & 4.33 & 2.81 \\
7 & 800 & 600 & 207.76 & 52.43 & 4.64 & 2.90 \\
3 & 800 & 6 & 215.48 & 58.01 & 4.80 & 2.95 \\
\hline
\end{tabular}


the formation of turbostratic layers [63]. The CHNS analyses also fit in with this, since the percentage of $\mathrm{H}-$ and $\mathrm{O}$-atoms falls with temperature. This indicates a decrease in functional groups and thus a lower disordered peak. The calculated crystallite sizes $\mathrm{L}_{\mathrm{a}}$ (see Table 8) increase with increasing final carbonization temperature, from $2.54 \mathrm{~nm}$ at $600{ }^{\circ} \mathrm{C}$ to $2.81 \mathrm{~nm}$ at $1000{ }^{\circ} \mathrm{C}$, though the biggest size is found at $800{ }^{\circ} \mathrm{C}$. This is in accordance with the works of Ferrari et al., who stated that for small crystallite sizes below $3 \mathrm{~nm}$ there is an opposing trend of the relation between the peak ratio and the crystallite size [34, 52, $60,63]$. Furthermore, the evolution of the peak ratio is explained by the introduction of two different carbonization regimes [64]. At first, the peak ratio increases with increasing carbonization temperature and is highest when carbonization is completed. This is attributed to a decrease in the order by the destruction of functional groups and restructuring in the precursor material. Here, the carbonization is completed at a temperature of around $800{ }^{\circ} \mathrm{C}$. At this point, the peak ratio is highest (see Table 8 ). By increasing the carbonization temperature above this limit, a second regime is reached. The peak ratio decreases again with increasing temperature, due to the ordering of graphitic domains and a shrinking the disorder peak in the Raman spectrum.

As the heating rate increases during carbonization from 6 to $600{ }^{\circ} \mathrm{C} \mathrm{h}^{-1}$, the FWHM and the calculated crystallite sizes stay roughly the same. This indicates that the effect of the heating rate is not as significant as with the temperature. However, a decrease in $\mathrm{FWHM}_{\mathrm{G}}$, and the peak ratio can be observed. Due to the slower heating rates, more ordered graphite structures can form. This leads to an increased $\mathrm{G}$ band and results in larger graphite crystallites.

\section{Conclusions}

The influence of carbonization parameters on the properties of viscose-based porous carbon fibers could be investigated in detail. Significant models could be found to assess the influence of both temperature and heating rate on yield, and specific surface area. By far the most important factor for the yield was the heating rate. In addition, it was possible to optimize both responses, even though some of them ran in opposite directions. Thus, a specific surface area of $156 \mathrm{~m}^{2}$ $\mathrm{g}^{-1}$ could be achieved at a high yield of $18.8 \%$ while keeping the carbonization temperature and heating rate as low as possible. The achieved specific surface areas are quite low for porous carbons, but it has to be considered that no activation was performed in this study. By using a chemical activation agent and/or an physical activation step using water vapor or $\mathrm{CO}_{2}$ an increase of the specific surface area to the range of commercial activated carbons (2000-3000 $\mathrm{m}^{2} \mathrm{~g}^{-1}$ ) should be possible. The obtained results indicate that viscose-based precursors are suitable to achieve activated carbons with sufficient specific surface areas at high yield. The findings of this fundamental study should also be transferable to viscose fibers from used clothing. However, this will be the task of later studies.

Acknowledgements The authors wish to thank the European Regional Development Fund (EFRE) and the Province of Upper Austria for financial support of this study through the Program IWB 2014-2020 (Project BioCarb-K).

Funding Open Access funding provided by Johannes Kepler University Linz.

Open Access This article is licensed under a Creative Commons Attribution 4.0 International License, which permits use, sharing, adaptation, distribution and reproduction in any medium or format, as long as you give appropriate credit to the original author(s) and the source, provide a link to the Creative Commons licence, and indicate if changes were made. The images or other third party material in this article are included in the article's Creative Commons licence, unless indicated otherwise in a credit line to the material. If material is not included in the article's Creative Commons licence and your intended use is not permitted by statutory regulation or exceeds the permitted use, you will need to obtain permission directly from the copyright holder. To view a copy of this licence, visit http://creativecommons.org/licenses/by/4.0/.

\section{References}

1. D. Klemm, B. Heublein, H.-P. Fink, A. Bohn, Cellulose: fascinating biopolymer and sustainable raw material. Angew. Chem. 44, 3358-3393 (2005). https://doi.org/10.1016/10.1002/ anie.200460587 (International edition in English)

2. L. Li, M. Frey, K.J. Browning, Biodegradability study on cotton and polyester fabrics. J. Eng. Fibers Fabr. 5, 155892501000500 (2018). https://doi.org/10.1016/10.1177/155892501000500406

3. E. Frank, L.M. Steudle, D. Ingildeev, J.M. Spörl, M.R. Buchmeiser, Carbon fibers: precursor systems, processing, structure, and properties. Angew. Chem. 53, 5262-5298 (2014). https:// doi.org/10.1016/10.1002/anie.201306129 (International edition in English)

4. F.M. Hämmerle, The cellulose gap: the future of cellulose fibres. Lenzing. Ber. 89, 12-21 (2011)

5. S. Breitenbach, A. Lumetzberger, M.A. Hobisch, C. Unterweger, S. Spirk, D. Stifter, C. Fürst, A.W. Hassel, Supercapacitor electrodes from viscose-based activated carbon fibers: significant yield and performance improvement using diammonium hydrogen phosphate as impregnating agent. C 6, 17 (2020). https:// doi.org/10.3390/c6020017

6. Y. Wang, Y. Song, Y. Xia, Electrochemical capacitors: mechanism, materials, systems, characterization and applications. Chem. Soc. Rev. 45, 5925-5950 (2016). https://doi. org/10.1016/10.1039/c5cs00580a

7. P. Simon, Y. Gogotsi, Materials for electrochemical capacitors. Nat. Mater. 7, 845-854 (2008). https://doi.org/10.1016/10.1038/ nmat 2297

8. C. Liang, N.J. Dudney, J.Y. Howe, Hierarchically structured sulfur/carbon nanocomposite material for high-energy lithium 
battery. Chem. Mater. 21, 4724-4730 (2009). https://doi. org/10.1016/10.1021/cm902050j

9. S. Wei, H. Zhang, Y. Huang, W. Wang, Y. Xia, Z. Yu, Pig bone derived hierarchical porous carbon and its enhanced cycling performance of lithium-sulfur batteries. Energy Environ. Sci. 4, 736 (2011). https://doi.org/10.1016/10.1039/c0ee00505c

10. I. Mochida, Y. Korai, M. Shirahama, S. Kawano, T. Hada, Y. Seo, M. Yoshikawa, A. Yasutake, Removal of $\mathrm{SO}_{\mathrm{x}}$ and $\mathrm{NO}_{\mathrm{x}}$ over activated carbon fibers. Carbon 38, 227-239 (2000). https://doi. org/10.1016/10.1016/S0008-6223(99)00179-7

11. J.Y. Yoo, C.J. Park, K.Y. Kim, Y.-S. Son, C.-M. Kang, J.M. Wolfson, I.-H. Jung, S.-J. Lee, P. Koutrakis, Development of an activated carbon filter to remove $\mathrm{NO}_{2 \& \text { nbsp; }}$ and $\mathrm{HONO}$ in indoor air. J. Hazard. Mater. 289, 184-189 (2015). https://doi. org/10.1016/10.1016/j.jhazmat.2015.02.038

12. A. Takdastan, A.H. Mahvi, E.C. Lima, M. Shirmardi, A.A. Babaei, G. Goudarzi, A. Neisi, M. Heidari Farsani, M. Vosoughi, Preparation, characterization, and application of activated carbon from low-cost material for the adsorption of tetracycline antibiotic from aqueous solutions. Water Sci. Technol. J. Int. Assoc. Water Pollut. Res. 74, 2349-2363 (2016). https://doi.org/10.1016/10.2166/wst.2016.402

13. Y. Chen, Y. Zhu, Z. Wang, Y. Li, L. Wang, L. Ding, X. Gao, Y. Ma, Y. Guo, Application studies of activated carbon derived from rice husks produced by chemical-thermal process-a review. Adv. Colloid Interface Sci. 163, 39-52 (2011). https:// doi.org/10.1016/10.1016/j.cis.2011.01.006

14. M. Sevilla, R. Mokaya, Energy storage applications of activated carbons: supercapacitors and hydrogen storage. Energy Environ. Sci. 7, 1250-1280 (2014). https://doi.org/10.1016/10.1039/ C3EE43525C

15. F. Gao, D.-L. Zhao, Y. Li, X.-G. Li, Preparation and hydrogen storage of activated rayon-based carbon fibers with high specific surface area. J. Phys. Chem. Solids 71, 444-447 (2010). https:// doi.org/10.1016/10.1016/j.jpcs.2009.11.017

16. T. Wang, K.S. Lackner, A. Wright, Moisture swing sorbent for carbon dioxide capture from ambient air. Environ. Sci. Technol. 45, 6670-6675 (2011). https://doi.org/10.1016/10.1021/es201 $180 \mathrm{v}$

17. V. Fierro, A. Szczurek, C. Zlotea, J.F. Marêché, M.T. Izquierdo, A. Albiniak, M. Latroche, G. Furdin, A. Celzard, Experimental evidence of an upper limit for hydrogen storage at $77 \mathrm{~K}$ on activated carbons. Carbon 48, 1902-1911 (2010). https://doi. org/10.1016/10.1016/j.carbon.2010.01.052

18. P.R. Shukla, S. Wang, H. Sun, H.M. Ang, M. Tadé, Activated carbon supported cobalt catalysts for advanced oxidation of organic contaminants in aqueous solution. Appl. Catal. B 100, 529-534 (2010). https://doi.org/10.1016/10.1016/j.apcatb.2010.09.006

19. C.-Y. Lu, M.-Y. Wey, K.-H. Chuang, Catalytic treating of gas pollutants over cobalt catalyst supported on porous carbons derived from rice husk and carbon nanotube. Appl. Catal. B 90, 652-661 (2009). https://doi.org/10.1016/10.1016/j.apcatb.2009.04.030

20. M.A. Yahya, Z. Al-Qodah, C.Z. Ngah, Agricultural bio-waste materials as potential sustainable precursors used for activated carbon production: a review. Renew. Sustain. Energy Rev. 46, 218-235 (2015). https://doi.org/10.1016/10.1016/j. rser.2015.02.051

21. H. Marsh, F. Rodríguez-Reinoso, Activated Carbon, 1st edn. (Elsevier, Amsterdam, 2006).

22. T.K. Enock, C.K. King'ondu, A. Pogrebnoi, Y.A.C. Jande, Status of biomass derived carbon materials for supercapacitor application. Int. J. Electrochem. 2017, 1-14 (2017). https://doi. org/10.1016/10.1155/2017/6453420

23. J. Yan, Q. Wang, T. Wei, Z. Fan, Recent advances in design and fabrication of electrochemical supercapacitors with high energy densities. Adv. Energy Mater. 4, 1300816 (2014). https://doi. org/10.1016/10.1002/aenm.201300816

24. J. Wang, S. Kaskel, KOH activation of carbon-based materials for energy storage. J. Mater. Chem. 22, 23710 (2012). https://doi. org/10.1016/10.1039/c2jm34066f

25. H.O. Pierson, Handbook of Carbon, Graphite, Diamond and Fullerenes: Properties, Processing and Applications (Noyes Publishers, Park Ridge, 1993).

26. A. Demirbas, Effects of temperature and particle size on biochar yield from pyrolysis of agricultural residues. J. Anal. Appl. Pyrolysis 72, 243-248 (2004). https://doi.org/10.1016/10.1016/j. jaap.2004.07.003

27. Z.Z. Chowdhury, M.Z. Karim, M.A. Ashraf, K. Khalid, Influence of carbonization temperature on physicochemical properties of biochar derived from slow pyrolysis of Durian wood (Durio zibethinus) sawdust. BioResources (2016). https://doi. org/10.1016/10.15376/biores.11.2.3356-3372

28. S. Masoudi Soltani, S.K. Yazdi, S. Hosseini, Effects of pyrolysis conditions on the porous structure construction of mesoporous charred carbon from used cigarette filters. Appl. Nanosci. 4, 551569 (2014). https://doi.org/10.1016/10.1007/s13204-013-0230-0

29. Y. Meng, X. Wang, Z. Wu, S. Wang, T.M. Young, Optimization of cellulose nanofibrils carbon aerogel fabrication using response surface methodology. Eur. Polym. J. 73, 137-148 (2015). https:// doi.org/10.1016/10.1016/j.eurpolymj.2015.10.007

30. Technical Association of the Pulp and Paper Industry. T.A.P.P.I. Standards; T 211 om-02: Ash in Wood, Pulp, Paper and Paperboard: Combustion at $525^{\circ} \mathrm{C}$. (2003)

31. N.K. Sahu, A. Andhare, Design of experiments applied to industrial process, in Statistical Approaches with Emphasis on Design of Experiments Applied to Chemical Processes. ed. by V. Silva (InTech, London, 2018)

32. A. Sadezky, H. Muckenhuber, H. Grothe, R. Niessner, U. Pöschl, Raman microspectroscopy of soot and related carbonaceous materials: spectral analysis and structural information. Carbon 43, 1731-1742 (2005). https://doi.org/10.1016/10.1016/j.carbo n.2005.02.018

33. X. Zhang, Q. Yan, W. Leng, J. Li, J. Zhang, Z. Cai, E.B. Hassan, Carbon nanostructure of kraft lignin thermally treated at 500 to $1000{ }^{\circ} \mathrm{C}$. Materials (2017). https://doi.org/10.1016/10.3390/ ma10080975

34. A.C. Ferrari, J. Robertson, Interpretation of Raman spectra of disordered and amorphous carbon. Phys. Rev. B 61, 14095-14107 (2000). https://doi.org/10.1016/10.1103/PhysRevB.61.14095

35. K. Le Van, T. Luong Thi Thu, Preparation of pore-size controllable activated carbon from rice husk using dual activating agent and its application in supercapacitor. J. Chem. 2019, 1-11 (2019). https://doi.org/10.1016/10.1155/2019/4329609

36. F. Tuinstra, J.L. Koenig, Raman spectrum of graphite. J. Chem. Phys. 53, 1126-1130 (1970). https://doi. org/10.1016/10.1063/1.1674108

37. A.L. Patterson, The Scherrer formula for X-ray particle size determination. Phys. Rev. 56, 978-982 (1939). https://doi. org/10.1016/10.1103/PhysRev.56.978

38. A. Pandey, T. Bhaskar, M. Stöcker, R.K. Sukumaran, Recent Advances in Thermochemical Conversion of Biomass (Elsevier, Amsterdam, 2015).

39. A. Colin Cameron, F.A.G. Windmeijer, An R-squared measure of goodness of fit for some common nonlinear regression models. J. Econ. 77, 329-342 (1997). https://doi.org/10.1016/10.1016/S0304 -4076(96)01818-0

40. F.L.H. da Silva, M.I. Rodrigues, F. Maugeri, Dynamic modelling, simulation and optimization of an extractive continuous alcoholic fermentation process. J. Chem. Technol. Biotechnol. 74, 176-182 (1999). https://doi.org/10.1016/10.1002/ (SICI)1097-4660(199902)74:2<176:AID-JCTB995>3.0.CO;2-C 
41. O. Onay, Influence of pyrolysis temperature and heating rate on the production of bio-oil and char from safflower seed by pyrolysis, using a well-swept fixed-bed reactor. Fuel Process. Technol. 88, 523-531 (2007). https://doi.org/10.1016/10.1016/j.fupro c. 2007.01.001

42. F. Rodríguez-Reinoso, M. Molina-Sabio, Activated carbons from lignocellulosic materials by chemical and/or physical activation: an overview. Carbon 30, 1111-1118 (1992). https://doi. org/10.1016/10.1016/0008-6223(92)90143-K

43. P.H. Brunner, P.V. Roberts, The significance of heating rate on char yield and char properties in the pyrolysis of cellulose. Carbon 18, 217-224 (1980). https://doi.org/10.1016/10.1016/00086223(80)90064-0

44. M.M. Tang, R. Bacon, Carbonization of cellulose fibers-I. Low temperature pyrolysis. Carbon 2, 211-220 (1964). https://doi. org/10.1016/10.1016/0008-6223(64)90035-1

45. R. Bacon, M.M. Tang, Carbonization of cellulose fibers-II. Physical property study. Carbon 2, 221-225 (1964). https://doi. org/10.1016/10.1016/0008-6223(64)90036-3

46. J.L. Figueiredo, J.A. Moulijn, Carbon and Coal Gasification: Science and Technology (Springer, Dordrecht, 1986).

47. C. Bouchelta, M.S. Medjram, M. Zoubida, F.A. Chekkat, N. Ramdane, J.-P. Bellat, Effects of pyrolysis conditions on the porous structure development of date pits activated carbon. J. Anal. Appl. Pyrolysis 94, 215-222 (2012). https://doi.org/10.1016/10.1016/j. jaap.2011.12.014

48. A.C. Lua, T. Yang, J. Guo, Effects of pyrolysis conditions on the properties of activated carbons prepared from pistachio-nut shells. J. Anal. Appl. Pyrolysis 72, 279-287 (2004). https://doi. org/10.1016/10.1016/j.jaap.2004.08.001

49. D.R. Helsel, R.M. Hirsch, Statistical Methods in Water Resources (USGS, 2002)

50. S.C. Abrahams, E.T. Keve, Normal probability plot analysis of error in measured and derived quantities and standard deviations. Acta Crystallogr. A 27, 157-165 (1971). https://doi. org/10.1016/10.1107/S0567739471000305

51. Z. Zheng, H. Xia, C. Srinivasakannan, J. Peng, L. Zhang, Utilization of Crofton weed for preparation of activated carbon by microwave induced $\mathrm{CO}_{2}$ \&nbsp; activation. Chem. Eng. Process. 82, 1-8 (2014). https://doi.org/10.1016/10.1016/j.cep.2014.05.001

52. I. Karacan, A. Gül, Carbonization behavior of oxidized viscose rayon fibers in the presence of boric acid-phosphoric acid impregnation. J. Mater. Sci. 49, 7462-7475 (2014). https://doi. org/10.1016/10.1007/s10853-014-8451-5

53. C. Moreno-Castilla, F. Carrasco-Marín., F.J. Maldonado-Hódar, J. Rivera-Utrilla, Effects of non-oxidant and oxidant acid treatments on the surface properties of an activated carbon with very low ash content. Carbon 36, 145-151 (1998). https://doi. org/10.1016/10.1016/S0008-6223(97)00171-1

54. I. Karacan, T. Soy, Structure and properties of oxidatively stabilized viscose rayon fibers impregnated with boric acid and phosphoric acid prior to carbonization and activation steps. J. Mater. Sci. 48, 2009-2021 (2013). https://doi.org/10.1016/10.1007/s1085 3-012-6970-5
55. W. Tongpoothorn, M. Sriuttha, P. Homchan, S. Chanthai, C. Ruangviriyachai, Preparation of activated carbon derived from Jatropha curcas fruit shell by simple thermo-chemical activation and characterization of their physico-chemical properties. Chem. Eng. Res. Des. 89, 335-340 (2011). https://doi. org/10.1016/10.1016/j.cherd.2010.06.012

56. L. Deng, R.J. Young, I.A. Kinloch, Y. Zhu, S.J. Eichhorn, Carbon nanofibres produced from electrospun cellulose nanofibres. Carbon 58, 66-75 (2013). https://doi.org/10.1016/10.1016/j.carbo n.2013.02.032

57. Z.Q. Li, C.J. Lu, Z.P. Xia, Y. Zhou, Z. Luo, X-ray diffraction patterns of graphite and turbostratic carbon. Carbon 45, 1686-1695 (2007). https://doi.org/10.1016/10.1016/j.carbon.2007.03.038

58. H. Takagi, K. Maruyama, N. Yoshizawa, Y. Yamada, Y. Sato, XRD analysis of carbon stacking structure in coal during heat treatment. Fuel 83, 2427-2433 (2004). https://doi.org/10.1016/10.1016/j. fuel.2004.06.019

59. A.C. Ferrari, S.E. Rodil, J. Robertson, Interpretation of infrared and Raman spectra of amorphous carbon nitrides. Phys. Rev. B 67, 841 (2003). https://doi.org/10.1016/10.1103/PhysRevB.67.15530 6

60. A.C. Ferrari, D.M. Basko, Raman spectroscopy as a versatile tool for studying the properties of graphene. Nat. Nanotechnol. 8 , 235-246 (2013). https://doi.org/10.1016/10.1038/nnano.2013.46

61. O.A. Maslova, M.R. Ammar, G. Guimbretière, J.-N. Rouzaud, P. Simon, Determination of crystallite size in polished graphitized carbon by Raman spectroscopy. Phys. Rev. B 86, 1036 (2012). https://doi.org/10.1016/10.1103/PhysRevB.86.134205

62. M.A. Amaral Junior, J.T. Matsushima, M.C. Rezende, E.S. Gonçalves, J.S. Marcuzzo, M.R. Baldan, Production and characterization of activated carbon fiber from textile PAN fiber. J. Aerosp. Technol. Manag. 9, 423-430 (2017). https://doi. org/10.1016/10.5028/jatm.v9i4.831

63. S. Yamauchi, Y. Kurimoto, Raman spectroscopic study on pyrolyzed wood and bark of Japanese cedar: temperature dependence of Raman parameters. J. Wood Sci. 49, 235-240 (2003). https:// doi.org/10.1016/10.1007/s10086-002-0462-1

64. S. Bernard, O. Beyssac, K. Benzerara, N. Findling, G. Tzvetkov, G.E. Brown, XANES, Raman and XRD study of anthracenebased cokes and saccharose-based chars submitted to high-temperature pyrolysis. Carbon 48, 2506-2516 (2010). https://doi. org/10.1016/10.1016/j.carbon.2010.03.024

Publisher's note Springer Nature remains neutral with regard to jurisdictional claims in published maps and institutional affiliations. 